\title{
A FATAL CASE OF MYOCARDIAL CONTUSION
}

\author{
BY \\ HUGH BARBER AND G. R. OSBORN \\ From the Derbyshire Royal Infirmary \\ Received March 18, 1941
}

The notes of this case are of interest, because a healthy young man died as the result of an uncomplicated myocardial contusion in the region of the left ventricle. The heart muscle was not ruptured, and there was no blood in the pericardial sac. Death was due to acute pulmonary œdema.

\section{CASE History}

On February 18, 1941, a sailor 22 years of age was found lying face downwards in the road, with the mark of a large motor-tyre across the left side of his back. It appears that one wheel of a loaded five-ton trailer passed over him. This was about midnight. He was admitted to the Derbyshire Royal Infirmary, where he died about four hours later.

The clinical evidence comes from an experienced house surgeon. The patient was semi-conscious and smelt of alcohol. There were some abrasions on the legs. There were no signs of head or chest injury. The heart and lungs were apparently normal. The problem appeared to be one of concussion, in a man who had taken alcohol. At 1.30 a.m. the pulse rate was 100 and regular; the respirations were 30 to the minute; and there was no obvious distress. At 2.0 there was no change, but by 2.30 the respirations were 40 and at 3.30 the pulse rate 120. About this time he began to bring up large quantities of frothy fluid and he died at 4 a.m.

\section{POST-MORTEM EXAMINATION}

The body was that of a strong man of 22 years. He was of average build and 5 feet 8 inches tall.

Externally there were multiple bruises and abrasions over both legs, the right iliac fossa, the nose, and the chin. There was an incomplete fracture of the second left rib in the mid-axillary line, and bruising extended for about an inch all around this, but the pleura was not torn. No other bones were fractured.

The mouth, trachea, and bronchi were filled with blood-stained froth. There were fairly generalized old pleural adhesions on both sides; no hæmothorax was present. The lungs showed general acute æedema, and bloodstained fluid poured from the cut surfaces. No chronic lung disease was 
found, and there were no large hæmorrhagic lesions similar to those seen in pulmonary concussion.

The pericardial sac was normal. Pericardial fluid was clear and only slightly increased.

The heart weighed 11 ounces. It was of normal size and shape. There was well-marked bruising of the left ventricle: the distribution of this is shown in the drawings. It was most severe over the whole lateral aspect (margo obtusus) and anteriorly near the apex. On section the bruising was seen to extend from the pericardial surface to a variable depth, this being mostly under half the thickness of the muscle ; in one place only, about the origin of the anterior papillary muscle, did it extend through the muscle and appear beneath the endocardium. The endocardium and valves were undamaged. Bruising was present about the bifurcation of the left coronary artery and followed the circumflex branch for about an inch. The right ventricle was normal, except for very slight bruising near the base. The two auricles and the great vessels were undamaged.

The skull, meninges, and brain were normal.

There was no blood in the peritoneal cavity, though there was bruising of the transverse colon and a small tear of the transverse mesocolon. The other abdominal organs were all normal.

The strong smell of alcohol when he was admitted was due to a bottle breaking in his clothing. The alcohol in the blood was only $85 \mathrm{mg}$. per 100 c.c.

Microscopically, many small groups of muscle fibres were seen to be ruptured, and this was most marked close to the pericardium. Hæmorrhage had taken place about these small ruptures and beneath the pericardium. The heart muscle otherwise showed a normal structure.

The lungs showed gross congestion of the capillaries and small arteries and veins. Most of the alveoli were filled with serous fluid containing few to many red blood cells. Phagocytic cells laden with hæmosiderin were numerous in the alveolar exudate. The bronchioles and bronchi contained a similar exudate. Free polymorphs were numerous throughout the walls of many of the bronchi, but there was little activity by mucus-secreting cells.

\section{COMMENTARY}

(1) The Type of Accident.

This was a clear case of compression of the thorax, where the weight on the back pressed him against the ground. There are numerous records of heart injury from such an accident, with and without fractures of the bones of the thorax. It is in the young, with an elastic chest wall, that fractures are less common.

Beck (1940) gives the following list of injuries as causes of non-penetrating wounds or contusions of the heart : falls from a height; impact of a heavy force to the chest; the impact of the steering wheel of a car (this is the commonest accident); the passage of a wheel over the chest; and impact by a fist, a golf ball, or a horse's hoof on the front of the chest. He writes: "Any 


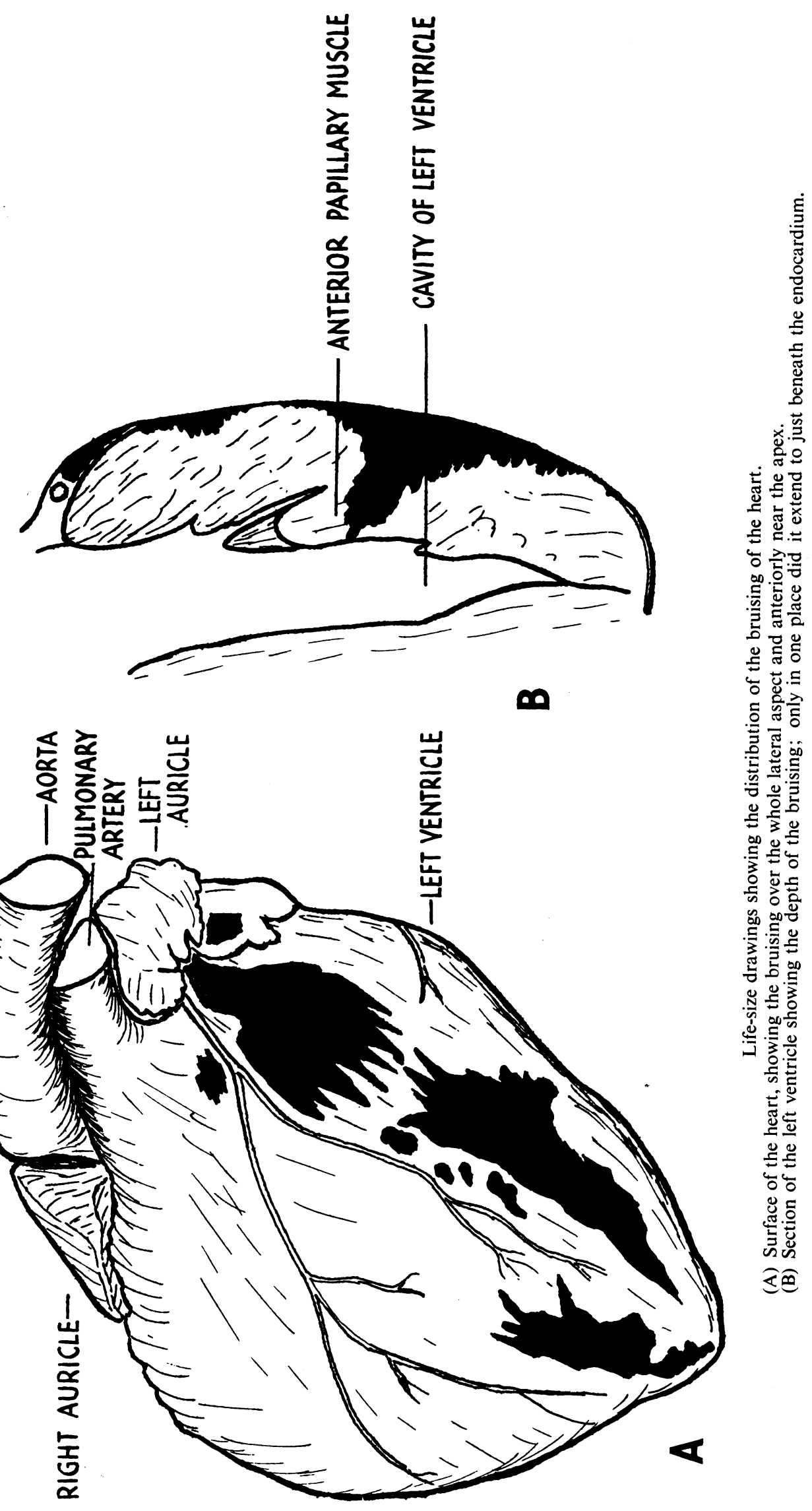


part of the heart can be bruised, any of the chambers ruptured, and any of the valves can be torn." He states that the heart may be ruptured if the body is engulfed and the lower part buried.

(2) The Site of the Heart Lesion and the Type.

In this case the lesion was confined to bruising of the wall of the left ventricle; it was sub-pericardial, as shown in the drawing. In the region of the papillary muscle it just reached the endocardium. There was no rupture of the muscle fibres nor injury of the pericardium.

In Warburg's series (1938 and 1940) of non-penetrating wounds of the heart, there were 66 post-mortem records, of which 12 showed rupture of the heart and 6 contusion of the myocardium without rupture. Pericarditis was recorded in a number of cases. Of late results, there were 6 cases of cardiac aneurysm. In a number of the records there was evidence of disease due to natural causes, and in some the evidence of trauma was not convincing. Bright and Beck (1935) analysed 152 cases of rupture of the heart from trauma, in which the left ventricle was ruptured in 37 , and each of the other chambers in 30 or more instances. In several instances more than one chamber was ruptured, and in 11 the inter-ventricular septum was torn. They recount 11 instances of failure without rupture, and 12 of recovery. Beck (1940), however, in commenting on these figures and comparing them with animal experiments, in which recovery is the rule, concludes that contusion of the myocardium is a common lesion, and is overlooked frequently.

An interesting study is the question of contusion developing chiefly under the endocardium. Warburg (1938) records such a condition, and also 6 cases of cardiac aneurysm following trauma. In these it would seem reasonable to suppose that the original lesion had been sub-endocardial. Groom (1897), in his case of delayed rupture of the left ventricle, noted that it appeared to have developed from within outwards.

We have one record of a partial rupture of the left ventricular wall extending from the endocardium about half way through the muscle. This lesion also involved the base of the papillary muscle. It was in a young man, who crashed in an aeroplane and had numerous other injuries, including rupture of the right ventricle.

Recently we have obtained a heart with sub-endocardial contusions following "cardiac massage" by a surgeon, when the heart ceased beating under an anæsthetic.

For three years we have made a special study of the heart in all post-mortem examinations after accidents. The variety of injuries met with confirm Beck's observations, that any part of the heart may be ruptured. The site of the lesion need not bear any obvious relation to the situation of the blow.

One justification for publishing this brief note is to emphasize the clinical interest to be found in medico-legal necropsies.

(3) The Clinical Symptoms.

The essential features were crushing of the chest; a latent period so far as obvious cardiac symptoms were concerned; and then, three and a half hours 
later, circulatory failure in the form of acute pulmonary œdema. This last symptom is of interest in view of the damaged left ventricle, and suggests failure of that part of the heart muscle. We noted similar symptoms (Barber, 1938) in a man who recovered after a blow over the chest. It was concluded that he had sustained a contusion of the left ventricle. A time interval, varying in length, between the injury and any symptoms suggesting heart muscle trauma is usual, and has been a feature of clinical histories from this hospital (Barber, 1940).

Kissane (1937) recorded a series of 15 cases of contusion of the heart: 2 were complicated by a valve rupture, 2 by auricular fibrillation, and in 3 there were fractures. Of the 8 remaining, 4 had symptoms of cardiac distress immediately, and in 4 there was some delay.

\section{SUMMARY}

A fatal case of contusion of the myocardium has been described; there was no rupture of the heart muscle. The morbid anatomy has been compared with other records.

Reference is made to clinical histories, already published from this hospital, suggestive of recovery from contusion of the myocardium.

\section{REFERENCES}

Bright, E. F., and Beck, C. S. (1935). Amer. Heart J., 10, 293.

Beck, C. S. (1940). Diagnosis and Treatment of Cardiovascular Disease. Edited by Stroud, Philadelphia, Vol. 2, 1157

Barber, H. (1938). Brit. med. J., 1, 433.

(1940). Ibid., 2, 520 .

Groom, W. (1897). Lancet, 1, 1202.

Kissane, R. W. (1937). Contusion of the Heart. The Ohio State University, Columbus.

Warburg, E. (1938 and 1940). Subacute and Chronic Pericardial and Myocardial Lesions due to Non-Penetrating Traumatic Injuries. Copenhagen.

- (1940). Brit. Heart J., 2, 271. 